EESTI NSV TEADUSTE AKADEEMIA TOIMETISED 1955. IV kd., nr. 4 ИЗВЕСТИЯ АКАДЕМИИ НАУК ЭСТОНСКОЯ ССР 1955. Том IV, ㅆ 4

\title{
КАТАЛИТИЧЕСКАЯ ТЕРМОПОЛИМЕРИЗАЦИЯ СРЕДНИХ ФРАКЦИЙ СЛАНЦЕВОЙ СМОЛЫ С СИНТЕТИЧЕСКИМ АЛЮМОСИЛИКАТОМ
}

\author{
А. Ф. ДОБРЯнСКии, \\ член-корреспондент Академии наук Эстонской ССР
}

\section{Э. Г. Ууㄷ}

Работы А. Ф. Добрянского и В. В. Тищенко $\left({ }^{2}\right)$ показали принципиальную возможность получения из сланцевой смолы стабильного дизельного топлива и смазочных масел при использовании в качестве катализатора активированного гумбрина. Очевидные преимущества твердого и легко регенерируемого синтетического алюмосиликатного катализатора, притом в непрерывном процессе, требовали проведения специального исследования.

В излагаемых далее опытах в качестве исходного материала была использована обесфеноленная $20 \%$ раствором едкого натра дизельная фракция смолы из генераторов полукоксования сланца (Кохтла-Ярве) .

Исходная фракция имела следующую характеристику: удельный вес $d_{4}^{20}=0,9096 ;$ вязкость при $20^{\circ} 7,05$ сст; коксуемость по Конрадсону $0,27 \%$; начало кипения - при $230^{\circ}$; до $249^{\circ}$ выкипает $10 \%$, до $289^{\circ}-50 \%$, до $346^{\circ}-95 \%$; конец кипения при $346^{\circ}(97,5 \%)$; молекулярный вес -209. Элементарный состав: C $-85,63 \% ; \mathrm{H}-11,60 \% ; \mathrm{S}-0,90 \% ; \mathrm{N}+\mathrm{O}-$ $1,87 \%$.

Основные опыты полимеризации проводились в металлических кубиках, снабженных обратным холодильником, термометром и терморегулятором, позволяющим поддерживать температуру в заданных пределах с точностью $2^{\circ}$. Обогрев кубиков осуществлялся с помощью тигельных печей.

В качестве катализатора во всех опытах применялся многократно регенерированный синтетический шариковый алюмосиликат. Для проведения полимеризации исходная дизельная фракщия (в количестве от 100 г до 1,5 кг при различных опытах) нагревалась в кубике в присутствии катализатора.

После полимеризации катализат сливался с катализатора, а оставшаяся на катализаторе часть его экстрагировалась в приборе Сокслета бензолом. Экстрагированная часть катализата составляла около $30 \%$ от всего катализата. После отгонки бензола,слитая часть и экстракт объединялись, профильтровывались и подвергались разгонке. 


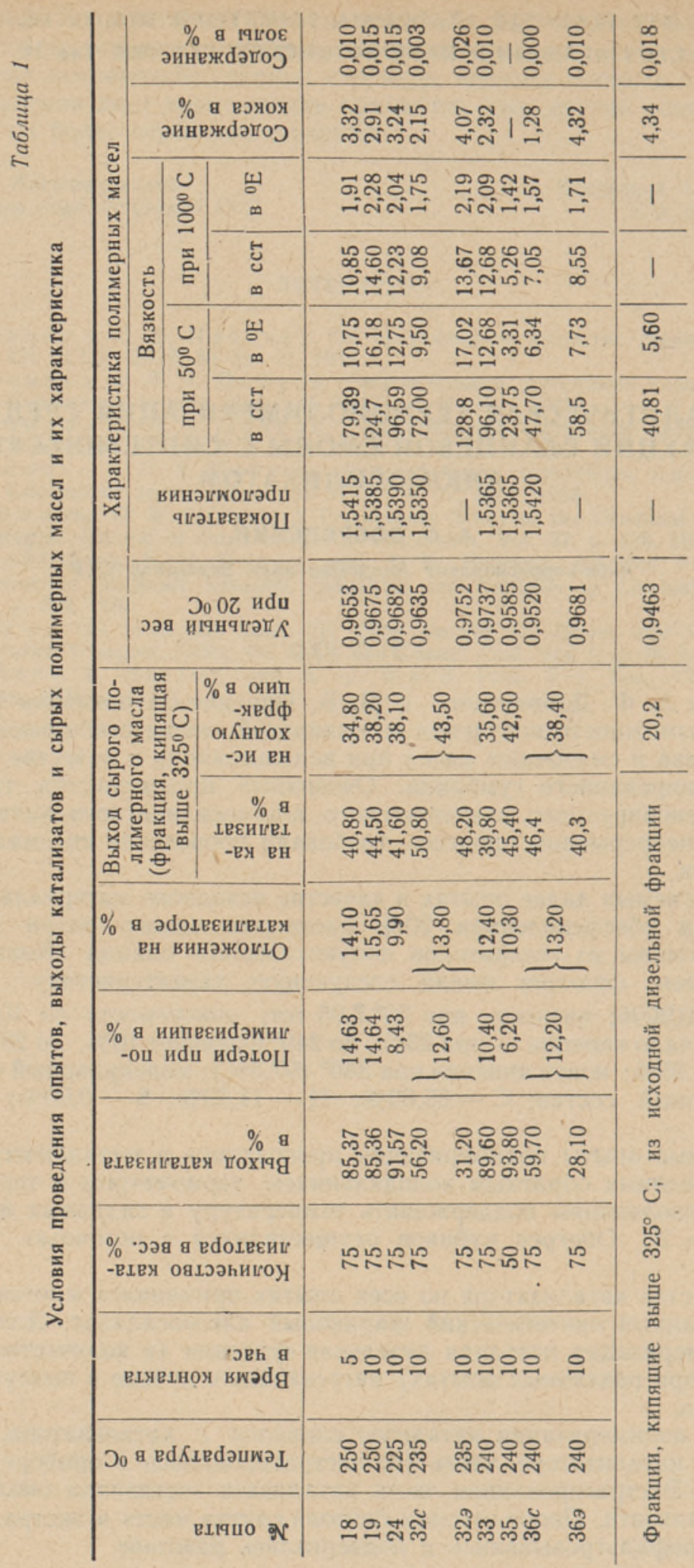


При атмосферном давлении отгонялись образовавшиеся легкие фракции (до $200^{\circ}$, в количестве $2-3 \%$ ) и затем в вакууме (при давлении 3 мм) - дизельная фракция до $325^{\circ}$ (при пересчете на атмосферное давление).

Процесс полимеризации характеризовался по выходу и свойствам фракции, кипящей выше $325^{\circ}$. Характеристики процессов полимеризации приведены в таблицах 1 и 2. В некоторых опытах слитая часть и экстракт из катализата не объединялись, а исследовались отдельно (обозначения с и

Таблица 2

Элементарный состав сырых полимерных масел (фракция, кипящая выше $325^{\circ} \mathrm{C}$ )

\begin{tabular}{|c|c|c|c|c|c|c|c|}
\hline \multirow{2}{*}{ ㄹ onыта } & \multirow{2}{*}{$\begin{array}{l}\text { Молеку- } \\
\text { лярный вес }\end{array}$} & \multicolumn{5}{|c|}{ Элементарный состав } & \multirow{2}{*}{$\begin{array}{c}\text { Эмпириче- } \\
\text { ская фор- } \\
\text { мула }\end{array}$} \\
\hline & & C & $\mathrm{H}$ & $\mathrm{S}$ & & $\mathrm{O}+\mathrm{N}$ & \\
\hline $\begin{array}{l}18 \\
19 \\
24 \\
32 c \\
329 \\
33 \\
35 \\
36 c \\
369\end{array}$ & $\begin{array}{l}392 \\
377 \\
341 \\
320 \\
350 \\
316 \\
307 \\
291 \\
308\end{array}$ & $\begin{array}{l}86,70 \\
87,06 \\
86,80 \\
87,11 \\
87,98 \\
87,80 \\
86,90 \\
86,60 \\
85,76\end{array}$ & $\begin{array}{l}11,65 \\
11,41 \\
11,59 \\
11,73 \\
10,50 \\
10,95 \\
11,20 \\
11,48 \\
11,60\end{array}$ & $\begin{array}{r}1,43 \\
1,40 \\
1,12 \\
1,01\end{array}$ & $\begin{array}{c}1,16 \\
1,52 \\
1 \\
1,90 \\
1,92 \\
2,64\end{array}$ & $\begin{array}{l}0,22 \\
0,13 \\
0,49\end{array}$ & $\begin{array}{l}\mathrm{C}_{28} \mathrm{H}_{46} \\
\mathrm{C}_{27} \mathrm{H}_{44} \\
\mathrm{C}_{25} \mathrm{H}_{40} \\
\mathrm{C}_{23} \mathrm{H}_{38} \\
\mathrm{C}_{25} \mathrm{H}_{36} \\
\mathrm{C}_{22} \mathrm{H}_{34} \\
\mathrm{C}_{21} \mathrm{H}_{34} \\
\mathrm{C}_{22} \mathrm{H}_{36}\end{array}$ \\
\hline
\end{tabular}

В опыте 33 был использован погон с концом кипения $325^{\circ}$ из исходной фракции.

С целью исследования возможности проведения полимеризации в непрерывном процессе с подвижным катализатором была построена лабораторная опытная установка, схема которой дана на рис. 1 .

Для проведения непрерывного процесса полимеризации исходная дизельная фракция из капельницы 2 выпускалась через трубку в реактор 1, заполненный катализатором и снабженный электрообогревом. Катализат после прохождения слоя катализатора через верхнюю трубку, холодильник 17 и водоотстойник 20 собирали в приемнике 21. Катализатор загружался вручную через трубку 12. Выгрузка катализатора проводилась механически, через выгружатель 10, вращение которого осуществлялось с помощью электромотора 22 и специального редуктора 13. Скорость вращения выгружателя, т. е. количество выгружаемого катализатора, регулировалась с помощью временного реле 19. Выгруженный катализатор собирался на фильтре 11. Қатализат, выгруженный вместе с катализатором, и часть катализата с мокрого катализатора профильтровывались через фильтр 11 и подавались с помощью стеклянного ртутного насоса 6 обратно в реактор. Температура опыта регулировалась с помощью терморегулятора 7 и реле 18 .

Выгруженный катализатор после фильтрования экстрагировался, как и при других опытах. Экстракт из катализатора и катализат; собранный в приемнике, разгонялись отдельно.

В таблицах 1 и 2 под обозначениями $36 c$ и 36 приведены данные о выходах и свойствах продуктов, полученных после 60 -часового пропуска исходной дизельной фракции через реактор.

Результаты исследований показывают, что при полимеризации обесфеноленной дизельной фракции сланцевой смолы в присутствии синтети- 
ческого алюмосиликатного катализатора при температурах $240-250^{\circ}$ в течение 10 часов можно получать после отгонки легких и средних фракций (до $325^{\circ}$ ) остаточные масляные фракции с уменьшенным содер-

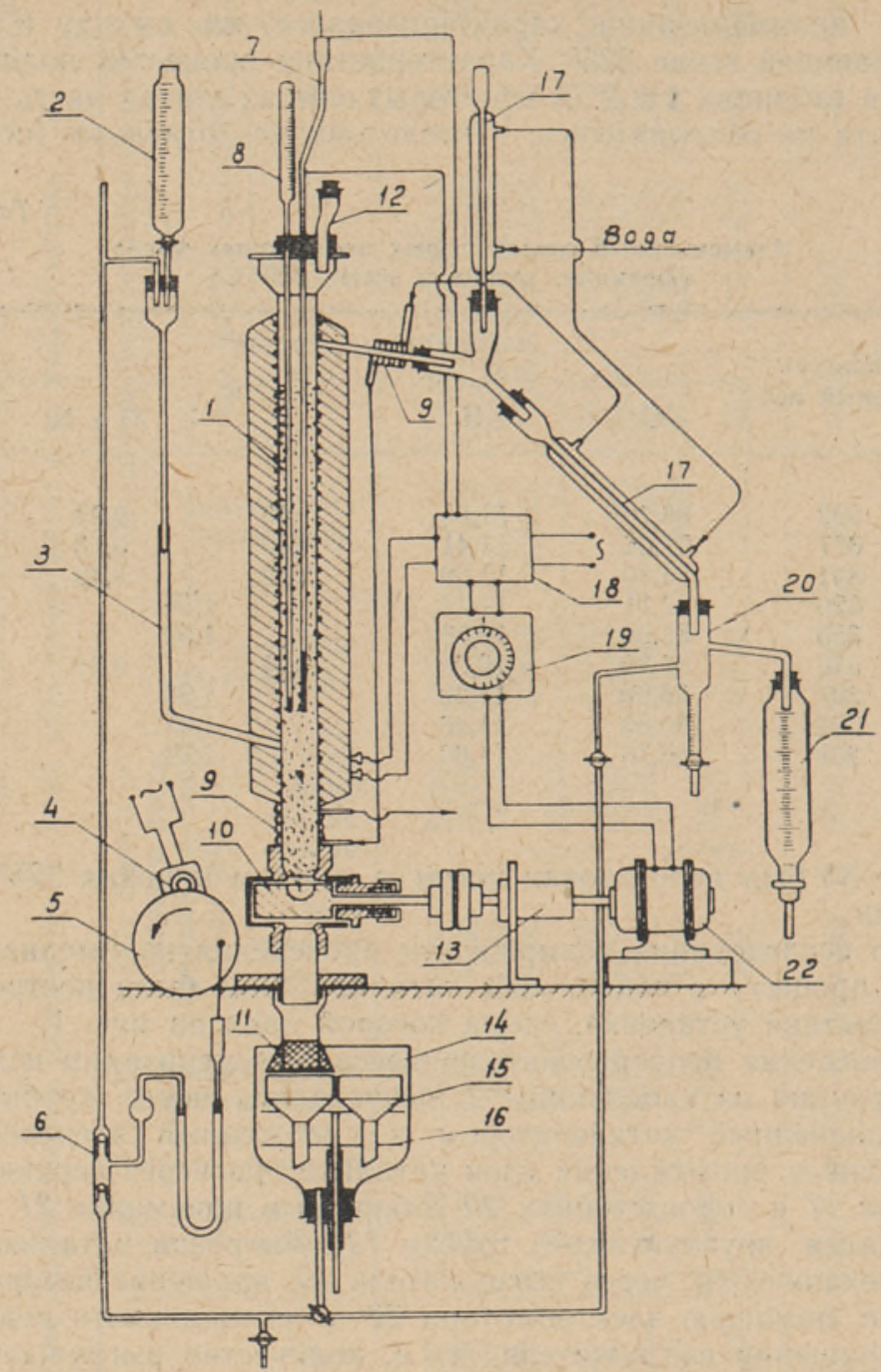

Рис. 1. Схема лабораторной опытной установки. 1 - реактор, 2 - капельница, 3 - питательная трубка, 4 - электромотор, 5 - привод насоса, 6 - стеклянный ртутный насос, 7 - терморегулятор, 8 - термометр, 9 - медная охлаждающая спираль, 10 - выгружатель для катализатора, 11 - сетка, 12 - трубка для загрузки катализатора, 13 - редуктор, 14 - приемник катализатора, 15 - фильтр, 16 - вращающаяся подставка для фильтров, 17 -холодильник, 18 - термореле, 19 - временное реле, 20 - водоотстойник, 21 - приемник катализата, 22 - электромотор.

жанием кислорода (табл. 2). Қак видно из таблицы 1, выход этих остаточных фракций в зависимости от условий проведения опыта составляет $34-43 \%$ на исходную дизельную фракцию.

Общие потери при полимеризации не превышают $15 \%$. 
Проведенные нами исследования показали, что повышение температуры процесса и увеличение времени контакта приводят в некоторых случаях к уменьшению вязкости и выхода остаточных фракций вследствие протекания реакций деполимеризации. Уменьшение количества катализатора сопровождается резким уменьшением вязкости остатка (оп. 35) и увеличением содержания кислородных и сернистых соединений в остатке. Увеличение количества катализатора, по всей вероятности, повышает эффективность процесса, но, с другой стороны, приводит к увеличению количества той части катализата, которую нужно экстрагировать из катализатора. Исходя из этого, мы считали нецелесообразным увеличить количества катализатора. Увеличение количества катализатора или времени контакта оказывается необходимым при осуществлении непрерывного процесса полимеризации, поскольку в остатке содержится большое количество кислородных и сернистых соединений и вязкость его остается низкой (табл. 1 и 2 ; оп. $36 c$ и 36 э).

Как видно из таблицы 1 , отложения на катализаторе составляют до $15 \%$. В промышленности каталитического крекинга такой процент отложения является недопустимым, так как регенерация катализатора связана с большими трудностями.

Для выяснения возможностей регенерации катализатора из опытов полимеризации, отдельные образцы подвергались прокаливанию при различных температурах $\left(300-600^{\circ}\right)$ без доступа воздуха. После прокаливания катализатора при $400^{\circ}$ в течение 20-30 мин. оставшийся на катализаторе кокс составляет не более $2,5 \%$ количества исходных отложений. Это предел, вполне приемлемый для проведения непрерывной регенерации катализатора.

Исходя из этого следует рекомендовать при регенерации катализатора из процесса полимеризации вначале крекинговать тяжелые смолистые отложения и после того провести регенерацию в потоке воздуха по принятой в промышленности крекинга схеме. В наших опытах регенерация проводилась в непрерывно действующем реакторе, схема которого являлась аналогичной схеме опытной установки полимеризации.

Хотя полученные при полимеризации обесфеноленной дизельной фракции остаточные масляные фракции напоминают средние и тяжелые индустриальные масла, непосредственное их использование из-за низкого индекса вязкости (не более $30-35$ ) и высокой коксуемости (табл. 1) невозможно.

По свойствам эти фракции до известной степени приближаются к масляным фракциям из тяжелых и сернистых нефтей.

Фракция, кипящая до $325^{\circ}$ в количестве $50-60 \%$ от всего катализата, представляет собой светлое, стабильное дизельное топливо с удовлетворительным цетановым числом. Полученное нами дизельное топливо имело следующие показатели качества: удельный вес $d_{20}^{20}=0,8779$; коксуемость - $0,017 \%$; коксуемость $10 \%$ остатка $-0,19 \%$; вязкость при $20^{\circ}-4$ сст; температура вспышки по $\mathrm{M}$-П $84^{\circ}$; начало кипения - при $200^{\circ}$; до $243^{\circ}$ выкипает $10 \%$, до $269^{\circ}-50 \%$, до $305^{\circ}-90 \%$; конец кипения - при $320^{\circ}(97,5 \%)$; анилиновая точка $50^{\circ}$; дизельный индекс 35 . Элементарный состав: $\mathrm{C}-87,50 \% ; \mathrm{H}-11,91 \% ; \mathrm{S}-0,59 \%$.

В процессе дальнейшего исследования полученные при полимеризации остаточные фракции подвергались вакуумной разгонке (остаточное давление 3 мм) в токе углекислоты. Полученные фракции смазочных масел очищались серной кислотой и после удаления гудрона профильтровывались через отбеливающую землю (гумбрин).

Данные по разгонке и очистке масел приведены в таблице 3. 
Разгонка и очистка остаточных фракций

\begin{tabular}{|c|c|c|c|c|c|c|c|}
\hline \multirow{3}{*}{$\begin{array}{c}\text { № } \\
\text { опыта }\end{array}$} & \multicolumn{2}{|c|}{$\begin{array}{c}\text { Разгонка остаточ- } \\
\text { ных фракций }\end{array}$} & \multicolumn{5}{|c|}{ Очистка масляных фракций } \\
\hline & \multirow{2}{*}{$\begin{array}{c}\text { Пределы } \\
\text { кипения } \\
\text { в }{ }^{\circ} \mathrm{C}\end{array}$} & \multirow{2}{*}{$\begin{array}{c}\text { Выход } \\
\text { фракций } \\
\text { в \% }\end{array}$} & \multirow{2}{*}{$\begin{array}{c}\text { Количе- } \\
\text { ство } \\
\mathrm{H}_{2} \mathrm{SO}_{4} \\
\text { в } \%\end{array}$} & \multirow{2}{*}{$\begin{array}{c}\text { Количество } \\
\text { отбеливаю- } \\
\text { щей земли } \\
\text { в \% }\end{array}$} & \multirow{2}{*}{$\begin{array}{c}\text { Потери } \\
\text { при } \\
\text { очистке } \\
\text { в \% }\end{array}$} & \multicolumn{2}{|c|}{$\begin{array}{l}\text { Выход очнщенных } \\
\text { смазочных масел }\end{array}$} \\
\hline & & & & & & $\begin{array}{c}\text { на } \\
\text { дестиллат } \\
\text { в } \%\end{array}$ & $\begin{array}{c}\text { на исходную } \\
\text { дизельную } \\
\text { фракцию } \\
\text { в \% }\end{array}$ \\
\hline $\begin{array}{l}18 \\
19\end{array}$ & $325-550$ & 90,0 & - & - & - & - & - \\
\hline $\begin{array}{l}32 c \\
32 \ni\end{array}$ & $\begin{array}{l}325-390 \\
390-450 \\
450-525\end{array}$ & $\begin{array}{l}27,7 \\
23,6 \\
33,8\end{array}$ & $\begin{array}{l}5 \\
5 \\
5\end{array}$ & $\begin{array}{l}\overline{15} \\
15\end{array}$ & $\begin{array}{r}7,0 \\
18,3 \\
19,6\end{array}$ & $\begin{array}{l}93,0 \\
81,7 \\
80,4\end{array}$ & $\begin{array}{r}11,2 \\
8,4 \\
11,8\end{array}$ \\
\hline $\begin{array}{c}\text { общий } \\
33 \\
36 c \\
\\
36 э \\
36\end{array}$ & $\begin{array}{r}\text { Выше } 325 \\
325-400 \\
400-480 \\
325-510 \\
325-400 \\
400-520\end{array}$ & $\begin{array}{r}85,1 \\
100,0 \\
44,5 \\
31,6 \\
78,2 \\
41,8 \\
33,3\end{array}$ & $\begin{array}{l}\overline{5} \\
5 \\
5 \\
5 \\
5 \\
5\end{array}$ & $\begin{array}{l}-15 \\
10 \\
10 \\
10 \\
10 \\
10\end{array}$ & $\begin{array}{l}\overline{19,2} \\
11,2 \\
13,4 \\
12,2 \\
10,8 \\
13,6\end{array}$ & $\begin{array}{l}84,9 \\
80,8 \\
88,8 \\
86,6 \\
87,8 \\
99,2 \\
86,4\end{array}$ & $\begin{array}{r}31,4 \\
28,8 \\
10,8 \\
7,4 \\
18,7 \\
4,2 \\
3,3\end{array}$ \\
\hline общий & & 75,6 & - & - & - & 87,9 & 25,7 \\
\hline
\end{tabular}

Как видно из приведенных данных, выход неочищенных фракций смазочных масел достигает $90 \%$ от остатка. После очистки серной кислотой и глиной общий выход очищенных масел составляет около $30 \%$ на исходную обесфеноленную фракцию.

В таблице 4 приведены данные технического анализа полученных масел.

Из таблицы 4 видно, что в зависимости от границ отбора фракций могут быть получены смазочные масла различных марок. Полученные масла полностью соответствуют нормам для различных легких и средних индустриальных масел типа веретенных, машинных и автотракторных марки AK (AK-6; АK-10; AK-15).

Индекс вязкости этих масел находится в пределах 50 и 70 и является приемлемым для автотракторных масел.

Полученные полимерные масла характеризуются удовлетворительным коксовым числом (не выше 0,9 для масел с вязкостью $25^{\circ} \mathrm{E}$ при $50^{\circ} \mathrm{C}$ ) и сравнительно низкой температурой застывания (ниже $-20^{\circ}$ ). Очищенное серной кислотой и глиной остаточное масло из опыта 33 (табл. 4) имело удовлетворительную вязкостную характеристику и температуру застывания (ниже $-20^{\circ}$ ), но коксуемость его оставалась высокой. Незначительное повышение коксового числа указывает на необходимость дестилляции масел.

В таблице 5 приведены элементарный состав полученных при полимеризации масел и данные структурно-группового анализа по методу $n$-d-M. Надежность этого метода при исследовании состава смазочных масел была проверена К. Ван-Несом и Х. Ван-Вестеном (') как на масляных фракциях из различных нефтей, так и на образцах синтетических масел. 


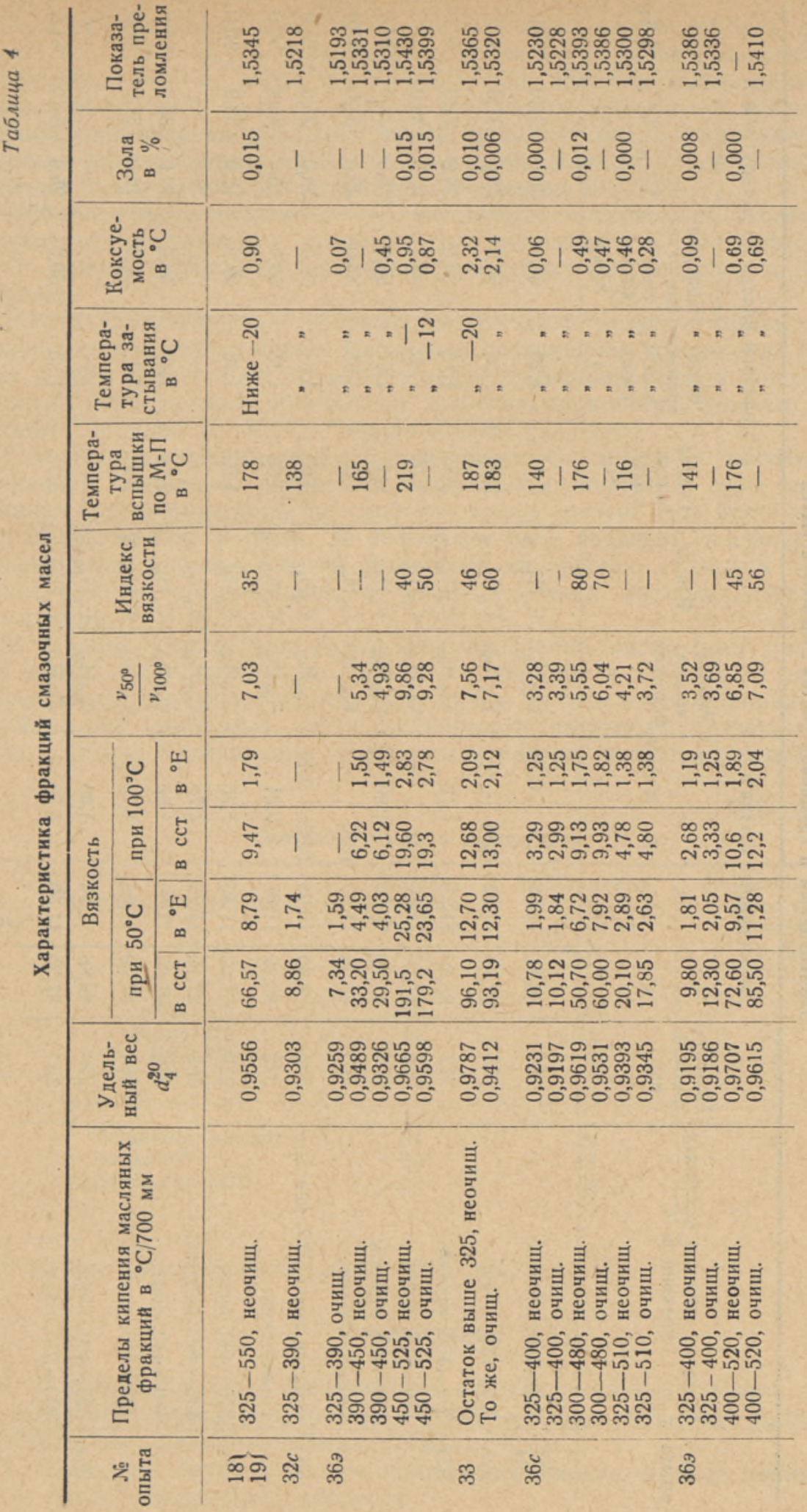


童

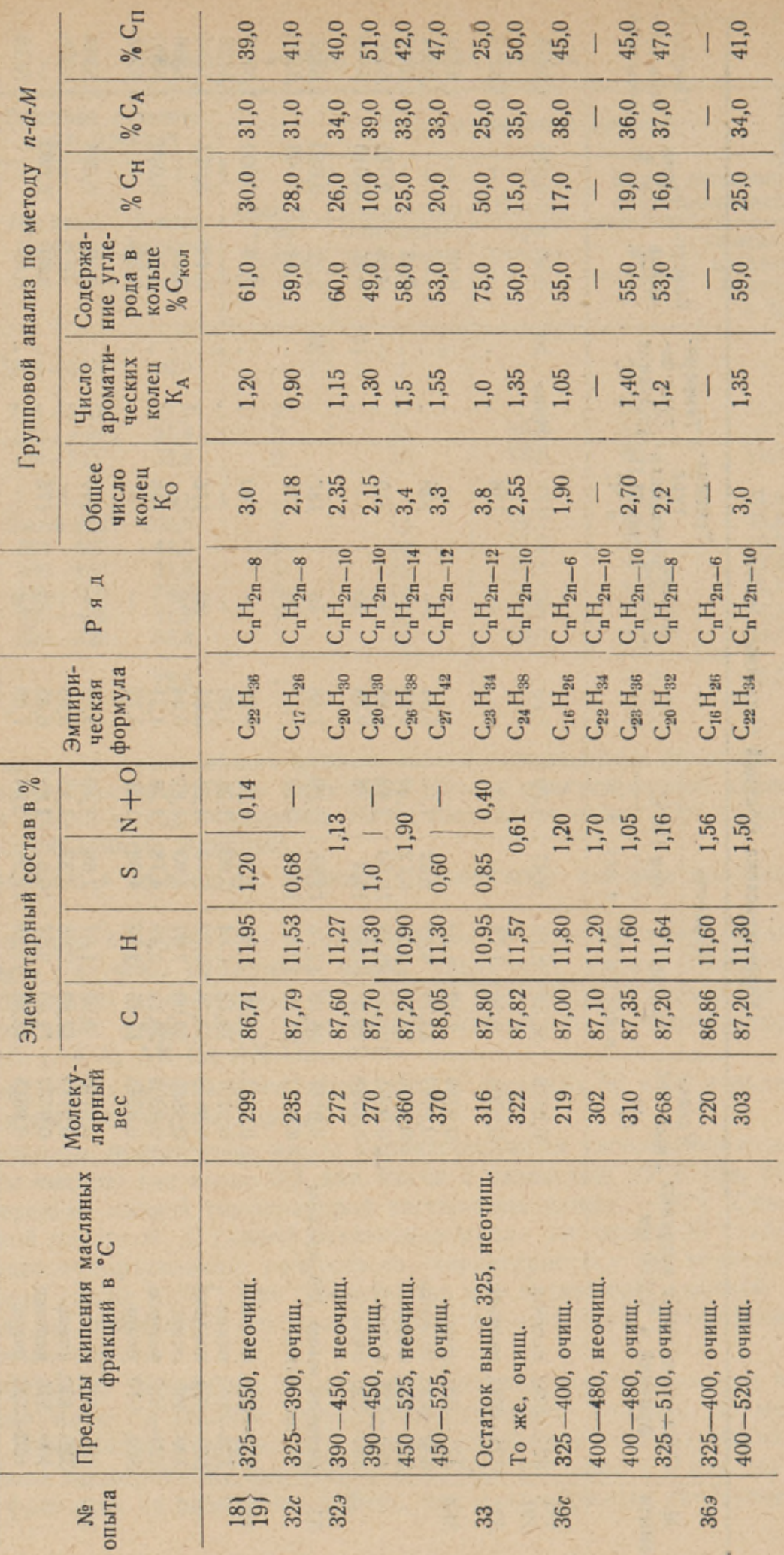


Хотя применимость этого метода в настоящем случае требует дополнительного изучения, полученные результаты могут оказааться полезными при оценке качества масел, полученных при полимеризации сланцевой дизельной фракции. Судя по данным группового анализа из таблицы 5 , главной составной частью этих масел являются би- и трициклические частично гидрированные ароматические углеводороды. Содержание углеводорода в алифатических структурах примерно $40-50 \%$.

Небезинтересно отметить, что увеличение содержания углерода в алифатических структурах после очистки происходит за счет нафтеновой части, причем содержание ароматических структур уменьшается незначительно.

Масла, полученные в непрерывном процессе полимеризации, мало отличаются от других масел. Несколько повышенное содержание кислорода и серы может быть объяснено недостаточным временем контакта в условиях непрерывного процесса и некоторыми конструктивными недостатками опытной установки (малая высота реактора).

Полученные образцы масел характеризуются довольно высоким содержанием стабильных сернистых соединений (содержание серы до $1 \%$ ). Влияние содержания серы на свойства масел требует еще дополнительного исследования, но вряд ли оно может быть вредным, поскольку, по литературным данным, многие сернистые соединения являются эффективными антикоррознонными, а также слабыми антиокислительными присадками.

В таблице 6 приведены результаты окисления очищенных полимерных масел в тонком слое по Папоку $\left({ }^{3}\right)$ при $250^{\circ}$ в течение 30 мин. Из приведенных данных видно, что полученные из дизельной фракции сланцевой смолы смазочные масла не уступают нефтяным смазочным маслам, особенно в отношении стабильности против лакообразования.

Таблица 6

Окисление масел в тонком слое

\begin{tabular}{|c|c|c|c|c|}
\hline $\begin{array}{l}\text { № } \\
\text { опыта }\end{array}$ & $\begin{array}{c}\text { Пределы кипения масла } \\
\text { в }{ }^{\circ} \mathrm{C}\end{array}$ & $\begin{array}{c}\text { Летучие } \\
\text { продукты } \\
\text { окисления } \\
\text { в \% } \\
\end{array}$ & $\begin{array}{c}\text { Растворимые } \\
\text { продукты } \\
\text { окисления } \\
\text { в \% }\end{array}$ & $\begin{array}{c}\text { Нерастворимые } \\
\text { продукты } \\
\text { окисления } \\
\text { в \% }\end{array}$ \\
\hline \multirow[t]{2}{*}{$\begin{array}{l}32 \\
33 \\
36 c \\
36 \ni\end{array}$} & $\begin{array}{r}450-525 \\
\text { Выше } 325 \\
400-480 \\
400-520\end{array}$ & $\begin{array}{l}78 \\
81 \\
89 \\
86\end{array}$ & $\begin{array}{r}14 \\
14 \\
8 \\
9\end{array}$ & $\begin{array}{l}8 \\
5 \\
3 \\
5\end{array}$ \\
\hline & $\begin{array}{l}\text { Машинное масло* } \\
\text { Автол } 10^{*} \\
\text { Авиамасло МК* }\end{array}$ & $\begin{array}{l}84 \\
80 \\
53\end{array}$ & $\begin{array}{l}16 \\
17 \\
34\end{array}$ & $\begin{array}{r}0 \\
3 \\
13\end{array}$ \\
\hline
\end{tabular}

* Данные заимствованы из книги К. К. Папока $\left({ }^{3}\right)$.

\section{Заключение}

1. В работе показана возможность синтеза смазочных масел путем полимеризации обесфеноленной дизельной фракции сланцевой смолы над синтетическим алюмосиликатным катализатором.

2. Показана осуществимость полимеризации как в виде периодического, так и непрерывного процесса. 
3. Наиболее благоприятными параметрами процесса можно считать температуру $240-250^{\circ}$, продолжительность контакта 10 часов и количество катализатора $75 \%$ от веса исходной фракции.

4. Из остаточных фракций катализатора (кипящих выше $325^{\circ}$ ) могут быть получены применяемыми в нефтяной практике методами (разгонка, кислотно-контактная очистка) различные марки индустриальных масел AK типа веретенных, машинных и автотракторных с выходом в $30 \%$.

5. Фракция $200-325^{\circ}$ (в количестве $43-49 \%$ на исходное сырье) представляет собой светлое стабильное дизельное топливо с дизельным индексом 35.

6. Отработанный в процессе полимеризации катализатор может быть регенерирован после крекинга (при $400^{\circ}$ в течение 20-30 мин.) смолистых отложений на катализаторе, согласно схемам, принятым в промышленности каталитического крекинга.

Поступила в редакцию 9 VII 1955

\section{ЛИТЕРАТУРА}

1. К. В ан-Нес и Х. В ан - Вестен, Состав масляных фракций нефти и их анализ, ИЛ, М., 1954.

2. А. Ф. Добр я н ски й и В. В. Т и щ ен ко, Каталитическая термополимеризация средних фракций сланцевой смолы, Сборник Института химии АН ЭССР кГорючие сланцы. Химия и технология», вып. 2, 1956.

3. К. К. П а пок, Моторные топлива, масла и жидкости, т. ІІ, Гостоптехиздат, М.-Л., 1953. 